\title{
Domain B: Knowledge and Culture
}

\begin{abstract}
In this chapter, we examine the role of knowledge processes in the form of local practice, research, innovation and education in agroecology transformations. Knowledge and power are intimately linked; the questions of 'what knowledge' and 'whose knowledge' is valued are vitally important. We review the informal (outside of institutions) and formal knowledge processes that have been found to support agroecology. These affirm and enable the knowledge systems of agricultural producers, especially those of women and youth. We further discuss how the combination of scientific knowledge with local and traditional knowledge is important in agroecology transformations. Unfortunately, mainstream knowledge systems often disable agroecology because they privilege outside and topdown processes of knowledge transfer that invalidate local, farmer and indigenous knowledges.
\end{abstract}

Keywords Research • Learning • Education • Cognitive justice • Peasant-to-peasant

The way knowledge is constructed, produced, shared and put to use is critically important in any shift to agroecology (Levidow et al. 2014; IAASTD 2008). But the knowledge required for agroecology is radically different from that available in mainstream institutions such as agricultural universities and policy think tanks (Pimbert 2018). This is mostly because

(C) The Author(s) 2021

C. R. Anderson et al., Agroecology Now!, https://doi.org/10.1007/978-3-030-61315-0_5 
agroecology develops in very context-specific ways. Knowledge of the local ecosystem, history and landscape is crucial, and much of that is in the hands of farmers and other local people, as well as often deeply linked with cultural practices. Agroecological transformation emerges from the interactions between cultural identity and the knowledge inherent in culturally grounded practice.

Thus, knowledge and power are intimately linked. What knowledges are enabled and valued? Who are acknowledged as valid holders and producers of knowledge? The answers are crucial in shaping the potential of transformations in agroecology. Struggles over knowledge play out across related areas of research, innovation and education. Here, the cosmovisions, epistemologies and validity of alternative agroecological knowledge systems come into conflict with the scientist and corporate control of the dominant knowledge system. In this context, the remit of learning and knowledge goes far beyond the adoption of specific agroecological techniques. Instead, it depends on, and in turn reinforces, wider processes of democratization, organization and inclusion. Agroecological knowledge, like all of these domains, is therefore deeply entwined with issues of governance.

\section{ENABLING CONDITIONS}

A great deal of agroecological knowledge, learning and innovation is produced, held and mobilized (deployed in political process of transformation) in the networks and organizations of indigenous peoples and food producers (see Boxes 5.1 and 5.2). This points to a need to actively transform and construct knowledge systems to reflect diversity and decentralization, promote dynamic adaptation and deepen democracy. Traditional ecological knowledge, indigenous knowledge and the knowledge of agroecological farmers must be brought into dialogue with scientific ways of knowing.

Such a shift demands a departure from the linear 'knowledge transfer' approach dominated by formal science and experts (Pimbert 2018). Agroecological knowledge must be developed through complex and ongoing processes centred on social learning through networks of diverse actors engaged in knowledge dialogues.

\section{Traditional Knowledge and Culture}

As we have seen above, agroecology is highly context specific; to be effective, it must be based on place-based, lived knowledge. Thus, traditional 
ecological knowledge (TEK) is central within it. TEK is in essence knowledge held by a society or culture that is related to their local environment. Globally, many traditional agricultural systems based on TEK resonate with agroecological principles, from East Asian rice-fish systems (combining aquaculture and rice cultivation) to Mexico's milpa-solar cropping systems (cultivating maize, beans and squash together on home plots called solares) or Andean waru-waru ridge fields, which control drought and frost.

The indigenous knowledge imbuing these agroecological systems is deeply intertwined with their cultural practices associated with managing and protecting forests and other ecosystems for wild food and medicinalplant gathering (Woodley et al. 2006). Many indigenous cultures pass traditional knowledge and genetic resources from generation to generation through ceremonies, stories, songs and oral histories.

Unfortunately, these practices and the knowledge associated with them are often viewed as antiquated, with little value for modern agriculture. Centuries of colonialism have also eroded them, not least through Western bias in development and research and the imposition of corporate knowledge and technologies. To enable agroecology, conserving and reviving traditional stores of local knowledge and practice are critical. So are enabling the cultural practices associated with stewarding biodiversity and territories and identifying the factors that impede or encourage indigenous elders' transferal of knowledge to younger generations (Woodley et al. 2006, p. 11).

The Globally Important Agricultural Heritage Systems (GIAHS) initiative, started in 2002 under the auspices of the Food and Agriculture Organization of the United Nations (FAO), now encompasses 59 sites in 22 countries that are recognized for their function as reservoirs of biodiversity, culture and traditional knowledge. The GIAHS initiative reflects an important intergovernmental commitment to preserving these knowledge systems. However, beneficial traditional practices also exist outside these recognized landscapes and it is important to acknowledge, protect and harness these processes where they are present.

\section{Horizontal Learning}

Horizontal learning is based on principles of Freirian pedagogy and is based on reciprocal learning dialogues and exchanges where the hierarchy between teacher and learner is intentionally dissolved and where all actors, offering their own experience and knowledge in the learning 
environment, are regarded as teacher-learners. Through a horizontal approach, these actors build capacity in terms of agroecological practice and politics but also as teachers, thus enabling the ongoing spread of agroecology in a horizontal pattern.

Colin Anderson et al. (2019) proposed that food producers and social movements must lead any transformative agroecology learning approach and that it must be based on four key characteristics or qualities (Fig. 5.1):

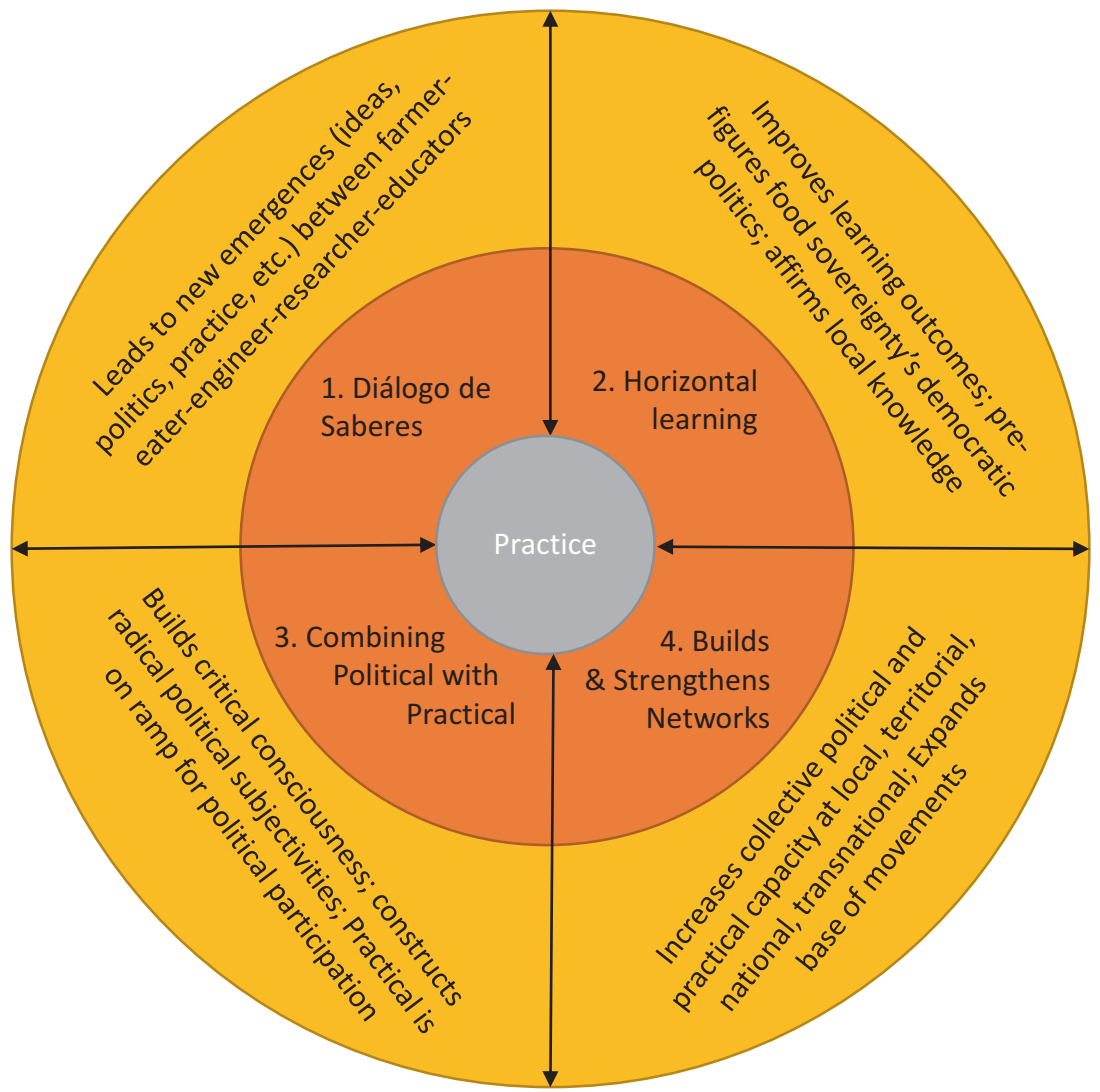

Fig. 5.1 Transformative agroecology framework by Anderson et al. (2019) involves a pedagogical approach that places practice as a central component of all training. It however integrates four pillars (the orange segments) to provide the 'connective tissue' to the political project of food sovereignty (the yellow circle) 
horizontal learning; diálogo de saberes (wisdom dialogue); combined practical and political knowledge; and building networks. Thus, while the protagonism of food producers and farmer organizations in agroecological learning is important, it is critical that methodologies and pedagogies go beyond 'the practical' and are linked to political work underway in territories.

Horizontal forms of adult learning among agroecological producers have been found to be vital in spreading agroecology (Mier y Terán Giménez Cacho et al. 2018; Anderson et al. 2019; McCune and Sánchez 2018). A well-known example is the farmer-to-farmer (campesino a campesino or $\mathrm{CaC}$, Box 5.1) methodology that originated in the 1980s in Central America. Under it, farmers come together to discuss their farms, lives and dilemmas and diagnose and solve problems collectively. Peter Rosset (2011, P. 169), discussing the CaC approach in Cuba, explains the effectiveness of the farmer-driven social process of $\mathrm{CaC}$ :

A fundamental tenet of $\mathrm{CaC}$ is that farmers are more likely to believe and emulate a fellow farmer who is successfully using a given alternative on their own farm than they are to take the word of an agronomist of possibly urban extraction. Whereas conventional extension can be demobilizing for farmers, $\mathrm{CaC}$ is mobilizing, as they become the protagonists in the process of generating and sharing technologies.

\section{Box 5.1 Movimiento Campesino a Campesino: Practical and Political Learning from Farmer to Farmer}

The Movimiento Campesino a Campesino $(\mathrm{CaC})$, or Farmer-toFarmer Movement, is one of the earliest and most successful efforts for promoting sustainable agriculture in Latin America. The extensive knowledge networks that are at the basis of the $\mathrm{CaC}$ methodology have been highly effective not only in generating and spreading sustainable agricultural practices on the ground but also in enabling farmers to build skills and organizational capacity.

$\mathrm{CaC}$ involves hundreds of volunteer and part-time campesino promotores working with thousands of farmers and with the support of dozens of technicians, professionals and local development organizations. They have used relatively simple small-scale experimentation, combined with horizontal (farmer-to-farmer) workshops in basic ecology, agro-pastoralism, agronomy, soil and water conservation, 


\section{Box 5.1 (continued)}

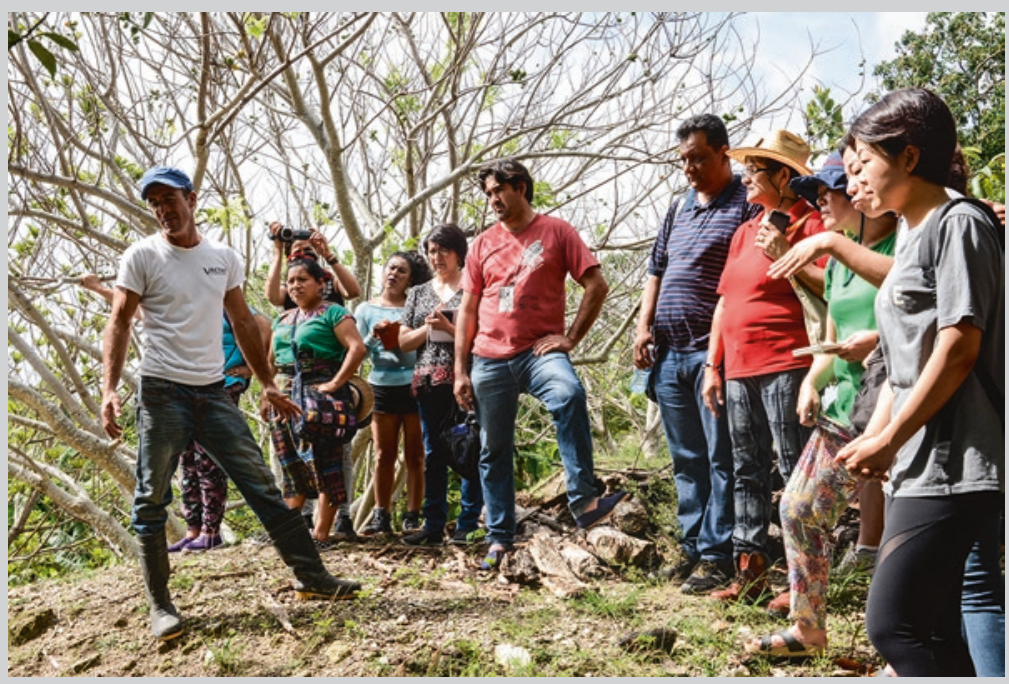

Fig. 5.2 Campesino a campesino learning in Latin America

soil building, small-scale livestock care, seed selection, crop diversification, integrated pest management and biological weed control (including integrating livestock). These approaches provide farmers with sufficient technical and ecological knowledge, as well as the necessary conviction, enthusiasm and pride to reverse degenerative processes and overcome the basic limiting factors in farm production. $\mathrm{CaC}$ has succeeded in regenerating tens of thousands of hectares of exhausted soils in the tropics.

Over the years, new insights emerged about the urgent necessity to accompany such practical farmer-to-farmer learning with structural social and political change. In an effort for agroecological experiences to spread both geographically and into the institutions that structurally shape agriculture's social, economic and political terrain, more recent $\mathrm{CaC}$ initiatives have included political training and 


\section{Box 5.1 (continued)}

organizing. The aim is to confront the structures and policies preventing the spread of agroecology and influence them to support it instead.

$\mathrm{CaC}$ has proven to be an effective social-organizational approach to developing a 'cadre' of agents capable of working collectively in technical and political work-such as social movement base-building, education or lobbying - to encourage the spread of agroecology. Building on these insights, the global peasant movement La Via Campesina (LVC) is creating learning processes centring on experimentation, innovation, recollection, sharing and the spread of agroecological methods under the umbrella of 'agroecology schools'. All of its schools combine technical and political education, as well as practice and theory. Their connection of $\mathrm{CaC}$ processes with schools for permanent training and practice-based reflection is a strong strategy for scaling agroecology out. LVC currently operates some 65 such schools around the world.

Source: La Via Campesina (2017); Holt-Giménez (2006)

Participatory and popular educational models of collective learning such as $\mathrm{CaC}$ are critical for the development of agroecology and for decentralizing agricultural development. Thus, building on the work of popular educators such as Paulo Freire, horizontal learning approaches by grassroots organizations in Brazil, Cuba, Nicaragua, India and other countries become self-perpetuating: they spread organically, as learners become teachers and farmers' organizations and social movements become stronger. The methods encourage deeper reflexive learning and in recent years have started to be linked with political training (McCune and Sánchez 2018), increasing the collective capacity of the networks in agroecology to influence the dominant food system. When technical education in agroecological practice is embedded in and linked to organizing within social movements, participants can develop a collective self-awareness of their situations, link lessons learned in local projects and articulate joint aspirations and demands. 
Farmer Field Schools (FFSs), pastoralist field schools and other such bodies have been championed by FAO and taken up by NGOs and farmer groups around the world. These too have been a powerful way of spreading and deepening knowledge of, for and by agricultural producers. The schools bring together groups of agricultural producers to develop appropriate solutions based on methods such as agro-pastoralism, conservation agriculture, organic farming and integrated pest management (IPM). In over 90 countries, FFSs have enabled agricultural producers to build knowledge, reduce pesticide and other external input use and shift towards more sustainable livelihoods. The field school approach emphasizes empowerment through increasing capacity among farmers and is based on farmer-centred experiential learning in the field. This allows producers to collectively observe, measure, analyse, assess and interpret agroecosystem relationships in decision-making.

In Indonesia, FFSs were effective in the spread of IPM. Their emphasis on marrying knowledge-work (training and research) and the strengthening of farmer's organizations and networks was critical in farmers' ownership of IPM across the country while simultaneously supporting the peasant movement. Interestingly, over time, a programme initially promoted by the field school initiated by FAO and the government evolved into what was then called 'community IPM'. This shifted the locus of agency to communities, emphasizing collective organization and institutionalizing IPM locally through horizontal FFS networks (Fakih et al. 2003). This, too, highlights the importance of embedding learning and training within broader networks of social movements and farmers' organizations (Anderson et al. 2019; see also Chap. 7).

\section{Box 5.2 Agroecology Training Programme of the Coordination Nationale des Organizations Paysannes (CNOP) in Mali}

The Coordination Nationale des Organisations Paysannes (CNOP) is a federation of 13 national peasant farmers' organizations in Mali. ${ }^{1}$ In 2011 the CNOP launched a training programme for farmer-trainers to scale out agroecology by building Malian

(continued)

\footnotetext{
${ }^{1}$ https://www.upadi-agri.org/coordination-nationale-des-organisations-paysannescnop-mali/.
} 


\section{Box 5.2 (continued)}

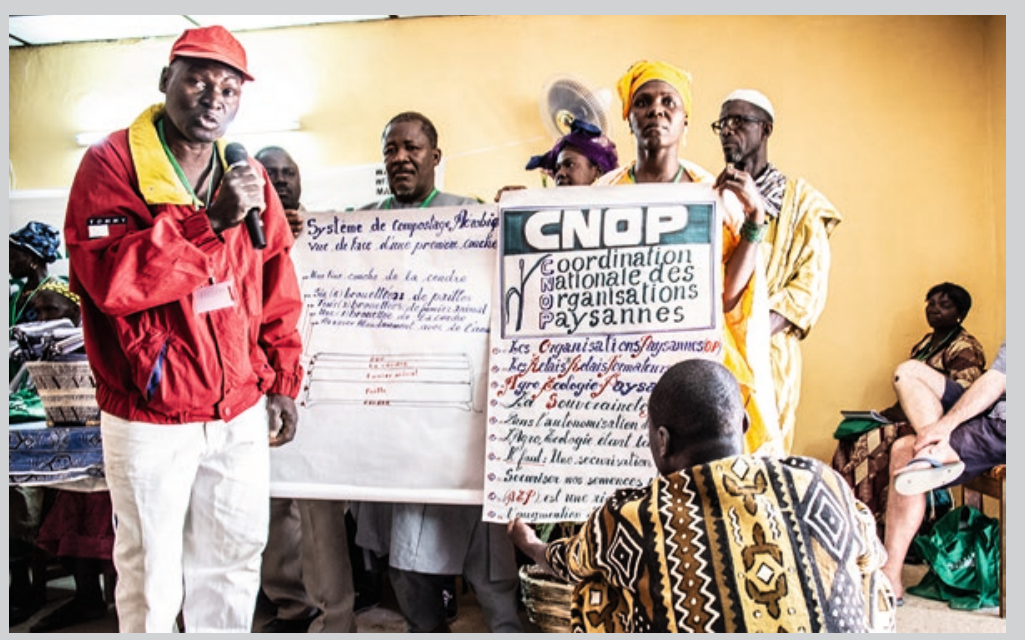

Fig. 5.3 Malian farmers at the Nyéléni International Center for Training in Peasant Agroecology (Photo credit: Colin Anderson)

farmers' capacity in peasant agroecology. The farmer-trainers are producers recognized by their peers. First, they participate in the training at the Nyéléni International Center for Training in Peasant Agroecology, located $140 \mathrm{~km}$ from Bamako. Then they share this knowledge in their cooperative, village or local producers' group.

Training sessions bring together farmers, pastoralists and fisherfolk from different regions and age groups, with an equal number of women and men, to share information on agroecological practices. Trainings are interactive, fostering the exchange of peasant knowledge, know-how and way of life. They cover local and global issues, struggles to be waged and agricultural policies for embedding territories in peasant agroecology.

These mechanisms - mixing participants from various agricultural sectors and different geographical areas and the equal number of male/female participants with at least $40 \%$ of young people-help to 


\section{Box 5.2 (continued)}

convey common messages and build knowledge collectively through horizontal forms of learning. By valuing each person's knowledge and skills, these educational choices help reduce inequality as well as social and cultural pressures while strengthening self-confidence and equity among participants.

Today, there are more than 500 farmer-trainers in peasant agroecology who have trained 20,000 producers across Mali. Trainees are often at the heart of informally organized regional commissions that maintain close links with the CNOP and help spur local economic activity around production units like collective fields worked by women and processing units for local juices, soap and parboiled rice. Through the trainees, these commissions help translate the spirit of trainings into concrete outcomes, creating synergy, innovation, income, employment, autonomy and dignity. From the training, a whole territory is on the move, mobilizing peasant organizations and communities and amplifying the positive impact of peasant agroecology in Mali.

Prepared in collaboration with Chantal Jacovetti, formerly responsible for peasant agroecology and land-related issues at the CNOP, currently working as a consultant on these themes and more broadly on agriculture in Mali and West Africa.

Learning across territories is important if agroecology is to make an impact within dominant food systems, because the integration and adaptation of knowledge from other places is key to sharing innovations. The international peasant movement LVC, for instance, has developed a worldwide agroecology learning network through peasant-to-peasant processes which have been described as the "motor" of agroecological scaling (Val et al. 2019). This advances agroecological knowledge from the perspective of farmers' experiences in their own territories, then disseminates it among territories, regions and countries. LVC has become, with other social movements and food producer organizations, a key protagonist in developing agroecological knowledge and mutual learning (Box 5.1). 


\section{Diálogo de saberes}

While the knowledge systems of traditional cultures, civil society and farmers are important, they are most powerful in dialogue with expert and scientific knowledge. A transformative agroecology is not anti-expert: instead, it demands that local and experiential knowledge be seen as equally important in agroecological development. In this context, the role of knowledge professionals such as researchers, teachers and technicians is oriented less towards spreading knowledge and more towards enabling the process of knowledge-sharing-especially co-producing knowledge with communities rather than producing and extending it to them. It is the job of knowledge professionals to provide advice and support to validate and improve agroecological practice, preferably through the collaborative co-production of knowledge with farmers (Pimbert 2018).

Dialogue between food producers and scientists, agricultural extensionists and educators allows agricultural producers an active, central role in testing, fine-tuning and scaling-out agroecological knowledge and practice, thereby capitalizing on their know-how and experience. Research methodologies for agroecology therefore emphasize participatory approaches to action, learning and analysis, with an emphasis on transdisciplinary ways of knowing that mobilize knowledge for social change and involve stakeholders in research (Méndez et al. 2015; Lamine 2018).

In this context it is important, however, to note two pervasive phenomena: the power imbalance between experts and non-experts and the ongoing incentives in science such as the pressure to publish with no accountability to actors outside research structures. These factors can encourage 'extractive' relationships that primarily benefit scientific partners (Levidow et al. 2014). Effective knowledge co-creation demands a substantial shift in institutional reward structures and professional norms and culture (Pimbert 2018). Charles Levkoe et al. (2019) argue that research compatible with transformative agroecology and food sovereignty should be based on three pillars: people (humanizing research relationships), power (equalizing power relations) and change (pursuing transformative rather than technocratic goals). Fortunately, in formal agroecology training and education, attention is paid increasingly to knowledge democracy, holistic agroecology and understanding agroecology as equally rooted in science, practice and politics. New pedagogical methods fostering this understanding include, for example, student collaborations in local agroecological dynamization, experiential learning and action learning. 


\section{Disabling Conditions}

The agroecological knowledge we describe above is rooted in a different logic from that of the centralized, decontextualized knowledge inherent in the dominant food system. Agroecology sits within wider agricultural knowledge, science and technology (AKST) systems, which benefit from substantial public and private funding around the world. Knowledge conceived, produced and distributed in these systems reflects norms of the dominant regime and serves its interests. This poses significant challenges to agroecology, which remains "on the margins of the agricultural sciences, as it is distant from the main scientific approach as well as from the technological regime and the larger economic and political dominant trends" (Vanloqueren and Baret 2009, p. 980).

Agricultural science, extension and education tend to validate and enable the knowledge and ways of knowing that reflect the dominant food regime while invalidating and disabling alternative knowledges (Pimbert 2018). Given the power of the private sector, notably agribusiness, the factor determining validation of knowledge is often its commercial productive potential. Over the past decades, agricultural research has increasingly focused on intensive industrial production. Public and private sectors have invested heavily in crop improvement programmes focused on biotechnological methods and agricultural chemicals, despite the arguable scarcity of the kinds of 'rigorous' evidence that is often demanded by detractors to prove the value of agroecological methods (Loevinsohn et al. 2013).

All over the world, the knowledge of farmers is increasingly being marginalized in agricultural development. International standardization and globalization have contributed to migration, poverty and the loss of local knowledge among small farmers and indigenous producers (Vogl et al. 2005). And while agroecology is in the main a transdisciplinary, produceroriented, collective approach, mainstream knowledge systems are deeply biased towards the knowledge of officially recognized experts, compartmentalized approaches to learning and top-down technology transfer (Chambers and Jiggins 1987). Traditional farming knowledge, practices and systems are displaced through the imposition of agricultural packages that are economically and materially dependent on external knowledge, technology and inputs.

Gaëtan Vanloqueren and Phillipe Baret (2009) illustrate how current science-related policy, along with the cultural and cognitive routines of 
scientists and institutions, limits how much mainstream innovation systems can benefit agroecology. Science-related policies are largely oriented towards growth and national competitiveness, while in many countries, public sector agricultural research and extension have been substantially scaled back. The ongoing corporate funding and control over research reinforces these trends, along with intellectual property rights that favour private sector research and development of patents, for instance, which undermine plant and livestock breeders' rights.

In this context, science and technocratic innovation that can be commercialized are prioritized, while innovations that meet social and ecological needs struggle to gain recognition and resource. Even though sustainability is a part of the discourse in agriculture, the mainstream agricultural knowledge system has become disconnected from farm and field, with its focus on the laboratory as the wellspring of new agricultural inputs and the 'rational' use of fertilizer, pesticides, herbicides and precision genetics. Reductionist approaches to knowledge development, such as those that focus on maximizing yield of single crops, are unable to account for the complex interactions in agroecological systems or their diverse, multifunctional benefits.

In this context, the knowledge and expertise of agricultural producers, citizens, small- and medium-sized enterprises, indigenous peoples and social movements are obscured and sidelined, or worse, extracted and commercialized. This can be seen in the case of biopiracy, when the traditional knowledge and genetic heritage of indigenous peoples are exploited for commercial gain, "particularly with the expansion of biotechnology for medicines, while they receive few or no material benefits and often risk resource depletion and the loss of their food sovereignty" (Woodley et al. 2006, p. 16).

The marginalization of local, non-expert and non-scientific ways of knowing (see also Chap. 9 on the discourse domain) reflects a more deeply rooted colonial view of knowledge. In it, non-Western, traditional and women's knowledge are 'othered', devalued and in some cases systematically erased (Santos 2015). Modern development has been especially blind to the knowledge and lives of indigenous peoples, women and other marginalized actors (Woodley et al. 2006). Omar Felipe Giraldo and Peter Rosset (2018) argue how ongoing approaches to agricultural development-largely led by actors in the global north and billed as 'sustainable agriculture'-continue to dehumanize and disempower communities, rendering them targets for expert knowledge and external management. 
The agricultural modernization approach violates the principles of cognitive justice (Visvanathan 2005) - that is, where the invalidation of farmers as knowledge-holders ultimately enables the imposition of many of the technologies and tenets of mainstream agriculture. The new knowledgetechnology packages (e.g. artificial intelligence) are, inevitably, geared to industrialized intensive agriculture, with all its attendant problems. By marginalizing alternative production systems, this process of modernization effectively overwrites traditional and indigenous knowledge systems and the lifeworlds that they sustain.

Giraldo and Rosset's (2018) analysis is similarly critical of the process of agricultural development where communities become disempowered, stripped of their agency and capacity for self-organization by the imposition of external technologies and methods. Modern development has been especially blind to, and damaging of, the knowledge and lives of indigenous peoples. The importance of cultural practices is often invisible in the sustainable development paradigm (Woodley et al. 2006). The loss of these cultural practices and indigenous languages, along with the displacement of indigenous people from traditional lands, severs the links between culture, traditional food systems and indigenous peoples' role as ecological stewards. Globalization and modernization threaten linguistic and cultural diversity, as do educational systems based in Western traditions and assimilation policies.

Beyond production, agricultural modernization has transformed the associated cognitive frameworks and cultural dynamics of food producers and communities. Decades of development led by Western science and corporate interests has depleted traditional ecological knowledge and practice. Not only have producers become materially and economically dependent on agribusiness inputs, they have also become ideologically committed to high-input, industrial-style approaches similar to the 'green revolution' of the 1960s and 1970s. In this context, local knowledge and corporate Western knowledge are often intertwined. Transformation cannot be addressed simply by incrementally advancing participatory research and development. It needs to be part of a much wider process confronting the material, cultural and spiritual legacies of colonialism (Waldmueller 2015).

Another critical global issue is the disproportionate influence of experts and institutions in the global north who shape the research, innovation and development agenda. Today, science and innovation are predominantly developed and controlled by experts and scientists in Europe and North America. Even within agroecology research, there are substantial power 
imbalances. Academics in industrialized countries conduct research wherever they like but do not publish in outlets based in non-industrialized countries, thus limiting the utility of the knowledge in the local context and language. Meanwhile, academics in non-industrialized countries rarely conduct research outside of their borders and publish wherever they can (Fernando Gomez et al. 2013). While knowledge gleaned abroad plays an important role in how agroecological innovation is shared, the contextspecific premise of agroecology does tip the balance towards local expertise. This includes the recognition and capacity of local research and researchers.

In addition, research on diversified agricultural production systems and agroecology is severely underfunded in most parts of the world (Carlisle and Miles 2013). In their study analysing projects funded through the 2014 US Department of Agriculture Research, Extension, and Economics budget, Marcia DeLonge et al. (2016) found that the allocation to agroecology was just $0.6-1.5 \%$ of the entire budget. Most of that was earmarked for on-farm agroecology techniques and only a small portion to the socio-economic elements such as strengthening farmer organizations and developing territorial governance systems like food policy councils that are essential for upscaling the system to achieve a sustainable food system.

When serving as UN Special Rapporteur on the Right to Food, Olivier De Schutter (2010) noted the lack of public and private sector funding for agroecology research "perhaps because [its] practices cannot be rewarded by patents"- even though they need prioritizing due to their "considerable and largely untapped potential". Without adequate funding for research, promising traditional and emerging methods of agroecology cannot be supported or analysed enough for scaling up. This lack of 'evidence' and validation has led to doubts about the efficiency and credibility of agroecological alternatives.

Another limitation to the development of agroecology in the knowledge domain is its incompatibility with the indicators commonly used to evaluate and monitor progress or success in agriculture (IPES-Food 2016; Binimelis et al. 2014). Indicators on progress tend to have a narrow focus on crop and livestock productivity and cash income. The benefits of agroecology, on the other hand, rarely lead to substantial increases in the productivity of single crops (but rather increase overall productivity and reduce external inputs) and may have non-cash benefits (through subsistence, barter or other systems of economic exchange) that are erased by conventional indicators. The many social and ecosystem functions of agroecology are rarely taken into consideration. 
Other progress indicators would be more consistent if applied to the economy of family agriculture. Conventional indicators such as profitability do not reveal how the management of agroecological systems generates 'added value' that includes, but goes beyond, crop diversity. Agroforestry and silvo-pastoral systems can create carbon sinks, increase agricultural biodiversity, reduce risk, produce diverse crops and livestock, preserve soil and water, maintain landscape elements and generate profits for agricultural producers. But these benefits are complex and difficult to measure, in part because they are slow, long-term processes.

Agroecology transformations demand new methods and approaches to evaluating success, including new indicators, to monitor and recognize the complex and multifunctional benefits of agroecological approaches. In this light, FAO is currently developing and testing a global analytical framework for the multidimensional assessment of the performance of agroecology: the Tool for Agroecology Performance Evaluation.

\section{REFERENCES}

Anderson, C. R., Maughan, C., \& Pimbert, M. P. (2019). Transformative Agroecology Learning in Europe: Building Consciousness, Skills and Collective Capacity for Food Sovereignty. Agriculture and Human Values, 36(3), 531-547.

Binimelis, R., Rivera Ferre, M. G., Tendero, G., Badal, M., Heras, M., Gamboa, G., et al. (2014). Adapting Established Instruments to Build Useful Food Sovereignty Indicators. Development Studies Research, 1(1), 324-339.

Carlisle, L., \& Miles, A. (2013). Closing the Knowledge Gap: How the USDA Could Tap the Potential of Biologically Diversified Farming Systems. Journal of Agriculture, Food Systems, and Community Development, 3(4), 219-225-219-225.

Chambers, R., \& Jiggins, J. (1987). Agricultural Research for Resource-Poor Farmers Part I: Transfer-of-Technology and Farming Systems Research. Agricultural Administration and Extension, 27(1), 35-52.

Charles Z. Levkoe, Josh Brem-Wilson \& Colin R. Anderson. (2019). People, power, change: three pillars of a food sovereignty research praxis, The Journal of Peasant Studies, 46:7, 1389-1412, 10.1080/03066150.2018.1512488

De Schutter, O. (2010). The Right to Food: Interim Report of the Special Rapporteur. New York, NY: The United Nations.

DeLonge, M. S., Miles, A., \& Carlisle, L. (2016). Investing in the Transition to Sustainable Agriculture. Environmental Science and Policy, 55, 266-273.

Fakih, M., Rahardjo, T., \& Pimbert, M. P. (2003). Community Integrated Pest Management in Indonesia: Institutionalising Participation and People Centred Approaches. London: IIED. 
Fernando Gomez, L., Rios-Osorio, L., \& Luisa Eschenhagen, M. (2013). Agroecology Publications and Coloniality of Knowledge. Agronomy for Sustainable Development, 33(2), 355-362.

Giraldo, O. F., \& Rosset, P. M. (2018). Agroecology as a Territory in Dispute: Between Institutionality and Social Movements. The Journal of Peasant Studies, $45(3), 545-564$.

Holt-Giménez, E. (2006). Campesino a Campesino: Voices from Latin America's Farmer to Farmer Movement for Sustainable Agriculture. Oakland, CA: Food First Books.

IAASTD. (2008). Agriculture at a Crossroads: Report of the International Assessment of Agricultural Knowledge, Science, and Technology. Library of Congress.

IPES-Food. (2016). From Uniformity to Diversity: A Paradigm Shift from Industrial Agriculture to Diversified Agroecological Systems. International Panel of Experts on Sustainable Food Systems (IPES).

La Via Campesina. (2017). Peasant Agroecology Schools and the Peasant-toPeasant Method of Horizontal Learning. https://foodfirst.org/wp-content/ uploads/2017/06/TOOLKIT_agroecology_Via-Campesina-1.pdf

Lamine, C. (2018). Transdisciplinarity in Research about Agrifood Systems Transitions: A Pragmatist Approach to Processes of Attachment. Sustainability, 10(4).

Levidow, L., Pimbert, M., \& Vanloqueren, G. (2014). Agroecological Research: Conforming — or Transforming the Dominant Agro-Food Regime? Agroecology and Sustainable Food Systems, 38(10), 1127-1155.

Loevinsohn, M., Sumberg, J., Diagne, A., \& Whitfield, S. (2013). Under What Circumstances and Conditions Does Adoption of Technology Result in Increased Agricultural Productivity? A Systematic Review Prepared for the Department for International Development. Brighton, UK: IDS.

McCune, N., \& Sánchez, M. (2018). Teaching the Territory: Agroecological Pedagogy and Popular Movements. Agriculture and Human Values, 36(3), 595-610.

Méndez, V. E., Bacon, C. M., Cohen, R., \& Gliessman, S. R. (2015). Agroecology: A Transdisciplinary, Participatory and Action-Oriented Approach. Roca Baton: CRC Press.

Mier y Terán Giménez Cacho, M., Giraldo, O. F., Aldasoro, M., Morales, H., Ferguson, B. G., Rosset, P., et al. (2018). Bringing Agroecology to Scale: Key Drivers and Emblematic Cases. Agroecology and Sustainable Food Systems, $42(6), 637-665$.

Pimbert, M. P. (2018). Democratizing Knowledge and Ways of Knowing for Food Sovereignty, Agroecology and Biocultural Diversity. In M. P. Pimbert (Ed.), Food Sovereignty, Agroecology and Biocultural Diversity. Constructing and Contesting Knowledge (pp. 259-321). London: Routledge. 
Rosset, P. M., Sosa, B. M., Jaime, A. M., and Lozano, D. R. (2011). The Campesino-to-Campesino agroecology movement of ANAP in Cuba: social process methodology in the construction of sustainable peasant agriculture and food sovereignty. J Peasant Stud 38(1), 161-191. https://doi.org/10.108 $0 / 03066150.2010 .538584$.

Santos, B. d. S. (2015). Epistemologies of the South: Justice Against Epistemicide. New York: Routledge.

Val, V., Rosset, P. M., Zamora Lomelí, C., Giraldo, O. F., \& Rocheleau, D. (2019). Agroecology and La Via Campesina I. The Symbolic and Material Construction of Agroecology Through the Dispositive of “peasant-to-peasant" Processes. Agroecology and Sustainable Food Systems, 43(7-8), 872-894.

Vanloqueren, G., \& Baret, P. V. (2009). How Agricultural Research Systems Shape a Technological Regime that Develops Genetic Engineering But Locks Out Agroecological Innovations. Research Policy, 38(6), 971-983.

Visvanathan, S. (2005). Knowledge, Justice and Democracy. In M. Leach, I. Scoones, \& B. Wynne (Eds.), Science and Citizens: Globalization and the Challenge of Engagement. London; New York Zed Books.

Vogl, C. R., Kilcher, L., \& Schmidt, H. (2005). Are Standards and Regulations of Organic Farming Moving Away from Small Farmers' Knowledge? Journal of Sustainable Agriculture, 26(1), 5-26.

Waldmueller, J. M. (2015). Agriculture, Knowledge and the 'colonial matrix of power': Approaching Sustainabilities from the Global South. Journal of Global Ethics, 11(3), 294-302.

Woodley, E., Crowley, E., de Pryck, J. D., \& Carmen, A. (2006). Cultural Indicators of Indigenous Peoples' Food and Agro-Ecological Systems. SARD Initiative commissioned by FAO and the International India Treaty Council.

Open Access This chapter is licensed under the terms of the Creative Commons Attribution 4.0 International License (http://creativecommons.org/licenses/ by $/ 4.0 /)$, which permits use, sharing, adaptation, distribution and reproduction in any medium or format, as long as you give appropriate credit to the original author(s) and the source, provide a link to the Creative Commons licence and indicate if changes were made.

The images or other third party material in this chapter are included in the chapter's Creative Commons licence, unless indicated otherwise in a credit line to the material. If material is not included in the chapter's Creative Commons licence and your intended use is not permitted by statutory regulation or exceeds the permitted use, you will need to obtain permission directly from the copyright holder.

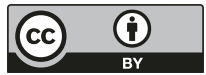

